\title{
Program Theory for Participatory Design
}

\author{
Claus Bossen \\ Department of Information Studies \\ and Digital Design \\ Aarhus University, Denmark \\ clausbossen@cc.au.dk
}

\author{
Christian Dindler \\ Department of Information Studies \\ and Digital Design \\ Aarhus University, Denmark \\ dindler@cavi.au.dk
}

\author{
Ole Sejer Iversen \\ Department of Information Studies \\ and Digital Design \\ Aarhus University, Denmark \\ oiversen@cavi.au.dk
}

\begin{abstract}
How does participatory design work and what are the links between investments in terms of time, people and skills, the processes and the resulting effects? This paper explores program theory as a way for Participatory Design (PD) to investigate and evaluate these issues. Program theory comes out of the evaluation field and is a way to make explicit the assumptions of how programs and projects are supposed to produce results by detailing the elements and causal links between them.
\end{abstract}

\section{CCS CONCEPTS}

- Human-centered computing $\rightarrow$ Participatory design;

\section{KEYWORDS}

Program theory, evaluation, participatory design

\section{ACM Reference Format:}

Claus Bossen, Christian Dindler, and Ole Sejer Iversen. 2018. Program Theory for Participatory Design . In PDC '18: Proceedings of the 15th Participatory Design Conference - Volume 2, August 20-24, 2018, Hasselt and Genk, Belgium. ACM, New York, NY, USA, 4 pages. https://doi.org/10.1145/3210604.3210638

\section{INTRODUCTION}

Recent years have seen a growing interest in the effects and outcomes of PD projects (e.g. [2, 6-8]) and how these are evaluated $[3,14]$. While this work, to some extent, supports the claim that PD can generate significant outcomes for participants such as improved skills, knowledge and working conditions, it also demonstrates that PD, as a research field, needs to further develop its understanding of the kinds of effects that are achieved, and how these may be causally linked to the activities conducted in PD projects. We acknowledge that several papers and books already formulate causality by addressing how PD activities are supposed to work, for example mutual learning through third spaces [10]. Our aim here is to extend this concern by exploring the potential of program theory for PD.

In this paper, we explore the idea of using program theory as a way to make explicit how PD projects and initiatives are expected to produce results for participants and society. Program theory

Permission to make digital or hard copies of all or part of this work for personal or classroom use is granted without fee provided that copies are not made or distributed for profit or commercial advantage and that copies bear this notice and the full citation on the first page. Copyrights for components of this work owned by others than the author(s) must be honored. Abstracting with credit is permitted. To copy otherwise, or republish, to post on servers or to redistribute to lists, requires prior specific permission and/or a fee. Request permissions from permissions@acm.org.

PDC '18, August 20-24, 2018, Hasselt and Genk, Belgium

(c) 2018 Copyright held by the owner/author(s). Publication rights licensed to ACM. ACM ISBN 978-1-4503-5574-2/18/08 . \$ $\$ 15.00$

https://doi.org/10.1145/3210604.3210638 is about "making explicit the underlying assumptions about how programs are expected to work" [11]. Briefly, this is typically done by formulating the causal relations between the planned inputs, activities of the process, and the outcomes and impacts that are expected to result. Here, 'causal' should be understood in the broadest sense within social theory (See, for example [4] on 'causation', and [18] on 'determinism').

For PD, a program theory could serve at least three purposes. First, modelling the relationships between various PD initiatives and their expected and documented outcomes provides a way to make explicit how and why particular PD techniques and practices achieve their intended aims. Thus, it can contribute to the already ongoing debate within PD, where, for example, it is documented how different workshop formats may lead to mutual learning or shared understanding. Second, program theory provides a basis upon which to develop evaluations of PD and can contribute to the emerging interest in this within the PD field. Third, for PD to gain more traction beyond research communities and find its way to, for example, large public IT projects [13], PD must be able to document its merits and how it works. Program theory provides a well-established framework for PD to document how, why and the extent to which it produces desired effects.

Below, we briefly outline the history and main ideas of program theory. We then provide two examples of how program theory can be applied, and conclude the paper by discussing the potential of program theory in $\mathrm{PD}$.

\section{PROGRAM THEORY FOR PD}

"Every program has a theory. Unfortunately, it may be implicit, fragmented, and not well conceptualized" [1].

Program theory comes out of the field of evaluation, and goes back to at least 1967, where Suchman suggested that such a theory would hypothesize that activity A would lead to outcome B, because it would influence process $C$ [11]. Making process causalities explicit opens the black box between input and effects, and makes evaluations more precise and increases learning outcomes, since it becomes possible to investigate why a project or program did or did not work. Hence, program theory evaluation has two components; a conceptual program theory, and an empirical evaluation. Since the 1970s, several works have elaborated this approach to evaluation under labels such as outcomes hierarchies, theory-of-action, theory-based evaluation, and program logic [11].

At its simplest, program theory depicts a single input, a process and an outcome: for example, designers and end-users participate in a workshop, which results in mutual learning. More complex program theories depict multiple inputs which combined result in outputs and has outcomes; for example, designers and end-users 
participate in workshops the output of which is technology that promotes work life quality and democracy. Often, program theory is depicted as boxes for inputs, processes, outputs, outcomes, and impacts, where each box can have several components, and the causal links between components are more or less explicit.

One purpose of program theory evaluation can be to test the causal relations of the theory in order to decide whether to continue a program as it is, change or end it. Assessing causal relations is particularly helpful for analysing whether failure is due to the program theory, or the implementation. Weiss [16] argues that distinguishing between the two is pertinent, since program theory concerns the 'mechanisms' that causes the result, while the implementation theory concerns how these are pursued through particular 'activities' [16, p. 49-50] . For example, when mutual learning is the desired outcome, an interdisciplinary workshop can be the activity for achieving this, while the mechanism is dialogue and perspective taking. Another purpose is to help program managers, in their daily practice, assess whether concrete activities have led to the desired outputs and outcomes (see [16] for a number of diagram examples of program theories).

The promise of program theory is to be able to gain knowledge about how programs work, and why they lead to the desired outcomes or not. Along the way, one also gains better knowledge about the causal relations, and becomes aware of faulty thinking and assumptions [11]. Program theory evaluation may also lead to the identification of hidden factors causing success or failure, as well as unintended outcomes [1].

The drawback of program theory evaluation, on the other hand, is that developing testable theory, translating this into an evaluation design, and actually conducting it, requires effort and time that is often not available. Further, while developing a program theory can be a fruitful way of engaging program staff or stakeholders, it may also generate controversy, since different assumptions of how and why a program works may come to the fore, such as disagreements about normative and causal theories about people's behaviour [1]

For the scholarly ambitious, program theory evaluation may also contribute to the development of sociological theory: "Program evaluation can make important contributions to social science theory if the program (independent variable) and measure of program process and outcome (dependent variables) are theoretical meaningful." [1]. 'Theory' does not have to be grand sociological conceptualisations but can be more mundane assumptions of why programs should work based on the expertise of involved professionals (school teachers, social workers, etc.). However, the issue of 'theory' is also of interest for policy and decision makers since they would likely be interested in knowing whether a program or some of its elements can be successfully applied in other contexts and domains.

\section{TWO EXAMPLES FROM PD LITERATURE}

In this section, we provide two brief examples of how program theory can be developed based on existing literature: One for PD in general, another for a specific PD project. For PD in general, we chose the introductory chapter of the Routledge International Handbook of Participatory Design [15], since this can be reasonably assumed to be one of the most updated and authoritative publications on PD at present. For the specific projects, we chose a paper by Whittle [17], because it evaluates a PD project and the paper is exceptionally clear in terms of project inputs, mechanisms, activities, and outputs, though not necessarily in those terms.

In both cases, we (the authors) independently identified inputs, mechanisms, activities, outputs, outcomes and impacts based on our reading of the two texts. We then met, discussed the differences, and cooperatively developed the two diagrams below using the concepts in the texts to stay close to these (Fig. 1 and 2).

\subsection{PD in general: Simonsen and Robertson 2012}

The purpose of the first diagram (Fig. 1) is to provide a first suggestion for what a program theory for PD in general might look like. The introductory chapter outlines the basic principles of PD, highlighting not only that users and designers are necessary input for the process, but also that appropriate design methods are necessary. In terms of outputs, outcomes and impacts the chapter, and hence Figure 1, reflect PD's commitment to both create better tools and products (output) and to the attainment of outcomes such as improved quality of work (outcome) and, ultimately, democracy and emancipation (impact). Going through the list of outputs addressed in the chapter, it is notable how these outputs range from physical products (e.g. better tools) to more intangible things such as learning and also new design methods.

A first insight from working out the diagram and program theory, was the usefulness in distinguishing between mechanisms and activities. Whereas 'workshops' are prolific and almost a standard ingredient of PD, it became clear that they are not themselves the central process or mechanism. Central PD mechanisms, such as 'active engagement' or 'collective reflection-in-action' can be facilitated in various ways, such as interaction with mock-ups or sketching activities. Second, while we were able to identify mechanisms from input to output, those from output to outcome and impact were less explicit. Thus, the next steps for developing a program theory for PD could be to include texts on sustaining PD (e.g. $[6,9])$. Of course, for a fully fledged program theory for PD to be developed, even more literature would need to be incorporated Fig. 1 merely serves to illustrate the potential of program theory for PD.

\subsection{Specific PD projects: Whittle 2014}

Applying a structured, formal understanding of PD in relation to its inputs, activities, outputs and impacts is not radically new. In 2014, Whittle [17] set out to understand the relation between the depth and scope of participation in PD projects and their outputs and outcomes. Hence, he conducted a comparative analysis of six PD projects detailing inputs, activities, outputs, and some intended impacts of the PD endeavours in the projects.

In comparison to Simonsen and Robertson [15], Whittle focuses on some more basic inputs as a necessity in the six PD projects (Fig. 2). Here, project funding, the presence of academic and nonacademic project participants as well as interdisciplinarity in the group of stakeholders are listed as inputs. As mechanisms, Whittle points to participation, equal partnership, knowledge sharing, 


\begin{tabular}{|c|c|c|c|c|c|}
\hline INPUT & Mechanism & Activity & Output & Outcome & Impact \\
\hline $\begin{array}{l}\text { - Users } \\
\text { - Designers } \\
\text { - Design methods } \\
\text { - Design material } \\
\text { - Tools and } \\
\text { techniques }\end{array}$ & $\begin{array}{l}\text { - Mutual learning } \\
\text { - (Genuine) Participation } \\
\text { - Active involvement } \\
\text { - Collective reflection-in-action } \\
\text { - Robust communication } \\
\text { - Equal power relations } \\
\text { - Participant engagement }\end{array}$ & $\begin{array}{l}\text { - Studying practice } \\
\text { - Sketching } \\
\text { - Interacting with mock-ups and } \\
\text { prototypes } \\
\text { - Envisioning future practice and } \\
\text { technology } \\
\text { - Workshops with designers and users }\end{array}$ & $\begin{array}{l}\text { - Better tools, products and } \\
\text { technologies } \\
\text { - Visions of better work } \\
\text { practice } \\
\text { - Articulated aims } \\
\text { - Better product and process } \\
\text { quality } \\
\text { - Increased knowledge } \\
\text { (designers learn about use } \\
\text { practice, users learn about } \\
\text { technology) } \\
\text { - New design methods } \\
\text { - Shared understanding }\end{array}$ & $\begin{array}{l}\text { - Extended skills } \\
\text { - Developed practice } \\
\text { - Voices heard in decision- } \\
\text { making. }\end{array}$ & $\begin{array}{l}\text { - (Workplace) } \\
\text { democracy } \\
\text { - Emancipation } \\
\text { - Shaping future } \\
\text { situations } \\
\text { - Equal power relations }\end{array}$ \\
\hline
\end{tabular}

Figure 1: Analysis of Simonsen and Robertson (2012)

\begin{tabular}{|c|c|c|c|c|c|}
\hline INPUT & Mechanism & Activity & Output & Outcome & Impact \\
\hline $\begin{array}{l}\text { - Money } \\
\text { - Researchers } \\
\text { - Ethical stand } \\
\text { - Academics } \\
\text { - Non-academics } \\
\text { - Interdisciplinarity }\end{array}$ & $\begin{array}{l}\text { - Participation } \\
\text { - Equal Partnership } \\
\text { - Knowledge sharing } \\
\text { - Continuously evaluate upskilling }\end{array}$ & $\begin{array}{l}\text { - Stakeholder meeting } \\
\text { - Co-Design workshops } \\
\text { - Co-Implementation } \\
\text { - Prototypes } \\
\text { - User trails } \\
\text { - Training of researchers in domain } \\
\text { - Side Benefits } \\
\text { - Upskilling workshops } \\
\text { - Training of users in research methods } \\
\text { - Citizen Science } \\
\text { - Ethnographic methods } \\
\text { - Focus groups } \\
\text { - User interviews } \\
\text { - Digital Ethnography }\end{array}$ & $\begin{array}{l}\text { - Academic papers } \\
\text { - Digital Prototypes } \\
\text { - Follow-on funding } \\
\text { - Match Funding } \\
\text { - Public engagement } \\
\text { - Appropriation } \\
\text { - Path to Commercialisation }\end{array}$ & $\begin{array}{l}\text { - Upskilled participants } \\
\text { - public engagement } \\
\text { - knowledge taken up by } \\
\text { other projects }\end{array}$ & $\begin{array}{l}\text { - Satisfy real social } \\
\text { needs } \\
\text { - Direct impact on } \\
\text { communities } \\
\text { - Sustained prototypes }\end{array}$ \\
\hline
\end{tabular}

Figure 2: Analysis of Whittle (2014)

continuous evaluation of the PD process and upskilling of project participants. These mechanisms are articulated and implemented through a range of PD activities such as codesign workshops, upskilling workshops, training of researchers in domains and twelve other PD activity formats. The inputs and PD processes led to a range of outputs, some of which are well recognized in PD research, while others are oftentimes neglected: digital prototypes, public engagement and follow-up funding are examples of recognized PD outcomes, whereas academic papers and a path to commercialization are often not explicitly mentioned as PD outputs. Whittle does not explicitly distinguish between outputs, outcomes and impact, as proposed in program theory, though the distinctions are implicitly made. The 'upskilled participant' is one of the intangible outcomes in the six projects as well as the extent to which the outputs were 'taken up by other projects'. As impact, Whittle describes the ability to sustain digital prototypes within the community and the ability to satisfy real social needs. These are intended and not necessarily accomplished impacts in the six projects.

One insight from working out a program theory based on Whittle was the strength of his structured approach, which enabled a comparative evaluation, and actually looked into one of PD central 'mechanisms" - participation. Though not based on program theory literature, it demonstrates its potential.

\section{DISCUSSION}

There is little room for detailed analysis based on program theory here, but through the two examples provided above we hope to have illustrated central principles and notions. In this section, we discuss the wider potentials of using program theory in PD.

Program theory is a way to make explicit the assumed causalities of projects and programs. Hence, it is different from 'methods' as outlined in Bratteteig et al. for PD as "a coherent set of organising principles and general guidelines" [5], and from 'frameworks' that 
seek to outline when to use which techniques and tools in PD [12] It is closer to efforts to detail PD results and what facilitates and hinders them [6], and to effects-driven IT development [8] though more formal and diagrammatic.

One particularly useful distinction made in program theory is the one between mechanism and activity, which has at least two potentials. First, it promotes a focus on what it is more precisely that leads to desirable results in PD processes and what the essential elements are. The most significant part of a workshop where participants, for example, develop a shared understanding may be relatively brief. The remainder of the workshop is used to create the right atmosphere, preparation, debriefing etc. In other words, we may distinguish between the central mechanism that we want to activate and the way it is activated. Second, it orients our attention towards the many ways in which any given mechanism may be activated through various formats. It suggests that we may study more systematically the impact that various activities have in terms of how the mechanism works.

On the level of the individual project, the construction of a program theory highlights the expected causality in terms of how particular processes are expected to lead to specific outputs and how outcomes will emerge. For practical purposes, this can enable and strengthen evaluations of progress as the project proceeds in order to check whether adjustments are needed (i.e. formative evaluation), or evaluation of results (summative evaluation). For theoretical purposes, program theory for individual projects can investigate how particular mechanisms are best facilitated through particular activities to achieve specific outcomes. A multitude of such specific, individual program theory-based evaluations may inform discussions within PD about tools and techniques. Whittle's text is one good example of this [17].

On the level of PD as a research community, the potential of program theory is to more systematically explore the various mechanisms employed in PD. How do activities best support mechanisms leading to outputs and outcomes? How do projects best support mechanisms leading to outcomes and impacts? Systematic inquiries would potentially lead to a more robust knowledge basis as reports are accumulated and individual mechanisms are assessed. Already, numerous publications exist through which a more detailed and comprehensive program theory (compared to the one sketched in Figure 1) could be elaborated. Pursuing this line of research does not mean abandoning the idea that PD is a situated activity and that processes and outcomes are bound to their particular context. Any given mechanism will be embedded in an activity and within the particular circumstances of the project, and skilfully setting this up is a central PD competence. As mentioned, program theory evaluation distinguishes between the program theory itself and its implementation, and developing the former does not diminish the importance of the latter.

In terms of understanding, documenting and reflecting on PD's ambitious goals relating to democracy, quality of life and emancipation, program theory offers a vocabulary for distinguishing between outputs, outcomes and impacts. Analysing past, current or future projects, allows researchers and practitioners to be explicit about how these ambitions are to be achieved and not least the extent to which they are achieved within the scope of the project. Long-term outcomes and impacts are typically shaped by factors 4 that are outside of the control of the individual project. Again, this is not to suggest that program theory can or should be used to predict or control PD processes; processes, outcomes and impacts are contingent and emergent phenomena. Yet, developing an explicit conception, detailing how PD works can be a way for PD researcher and practitioners to improve projects, and - not least - a way to convince stakeholders outside the community about PD's merits and thus increase its ability and 'will to succeed' [13].

We are not suggesting that PD should become more "scientific" or that program theory should replace focus on the activist or artistic practices of PD. Rather, we suggest that program theory, like such approaches, is a kind research inquiry that can be explored and further developed within PD. In our view, program theory offers ways to strengthen PD research within the community, as well as a way to document and communicate PD's potential to policymakers and decision-makers outside the community.

\section{REFERENCES}

[1] Leonard Bickman. 1987. The functions of program theory. New directions for evaluation 1987, 33 (1987), 5-18.

[2] Claus Bossen, Christian Dindler, and Ole Sejer Iversen. 2010. User gains and PD aims: assessment from a participatory design project. In Proceedings of the 11th Biennial Participatory Design Conference. ACM, 141-150.

[3] Claus Bossen, Christian Dindler, and Ole Sejer Iversen. 2016. Evaluation in participatory design: a literature survey. In Proceedings of the 14th Participatory Design Conference: Full papers-Volume 1. ACM, 151-160.

[4] Henry E Brady. 2008. Causation and explanation in social science. In The Oxford Handbook of Political Science.

[5] Tone Bratteteig, Keld Bødker, Yvonne Dittrich, Preben Holst Mogensen, and Jesper Simonsen. 2012. Organising principles and general guidelines for Participatory Design Projects. Routledge Handbook of Participatory Design (2012), 117.

[6] Tone Bratteteig and Ina Wagner. 2016. What is a participatory design result?. In Proceedings of the 14th Participatory Design Conference: Full papers-Volume 1. ACM, 141-150.

[7] Julia A Garde and Mascha C Van Der Voort. 2014. Participants' view on personal gains and PD process. In Proceedings of the 13th Participatory Design Conference: Short Papers, Industry Cases, Workshop Descriptions, Doctoral Consortium papers, and Keynote abstracts-Volume 2. ACM, 79-82.

[8] Morten Hertzum and Jesper Simonsen. 2010. Effects-Driven IT Development: A Strategy for Sustained Participatory Design and Implementation. In PDC 2010: The 11th Biennial Participatory Design Conference. Association for Computing Machinery, 61-70.

[9] Ole Sejer Iversen and Christian Dindler. 2014. Sustaining participatory design initiatives. CoDesign 10, 3-4 (2014), 153-170.

[10] M.J. Muller and A. Druin. 2012. Participatory design: The third space in humancomputer interaction. The Human-Computer Interaction Handbook: Fundamentals, Evolving Technologies, and Emerging Applications (2012), 1125-1154. cited By 9.

[11] Patricia J Rogers, Anthony Petrosino, Tracy A Huebner, and Timothy A Hacsi. 2000. Program theory evaluation: Practice, promise, and problems. New directions for evaluation 2000, 87 (2000), 5-13.

[12] Elizabeth B-N Sanders, Eva Brandt, and Thomas Binder. 2010. A framework for organizing the tools and techniques of participatory design. In Proceedings of the 11th biennial participatory design conference. ACM, 195-198.

[13] Dan Shapiro. 2005. Participatory design: the will to succeed. In Proceedings of the 4th decennial conference on Critical computing: between sense and sensibility. ACM, 29-38.

[14] Jesper Simonsen and Morten Hertzum. 2012. Real-use evaluation of effects: emergency departments aiming for'Warm Hands'. In Proceedings of the 12th Participatory Design Conference: Exploratory Papers, Workshop Descriptions, Industry Cases-Volume 2. ACM, 69-72.

[15] Jesper Simonsen and Toni Robertson. 2012. Routledge international handbook of participatory design. Routledge.

[16] Carol H Weiss. 1997. Theory-based evaluation: Past, present, and future. New directions for evaluation 1997, 76 (1997), 41-55.

[17] Jon Whittle. 2014. How much participation is enough?: a comparison of six participatory design projects in terms of outcomes. In Proceedings of the 13th Participatory Design Conference: Research Papers-Volume 1. ACM, 121-130.

[18] Raymond Williams. 2014. Keywords: A vocabulary of culture and society. Oxford University Press. 